\title{
Chemical Modification of Pseurotin A: One-pot Synthesis of Synerazol and Pseurotin $E$ and Determination of Absolute Stereochemistry of Pseurotin E
}

\author{
Minoru Ishikawa, Tomohisa Ninomiya
}

Received: July 22, 2008 / Accepted: October 16, 2008

(C) Japan Antibiotics Research Association

\begin{abstract}
Two natural products, synerazol and pseurotin E, were synthesized from the natural product pseurotin A in $58 \%$ and $57 \%$ yields, respectively in one-pot procedures. This work also establishes the absolute stereochemistry of pseurotin E.
\end{abstract}

Keywords pseurotin A, synerazol, pseurotin E, chemical modification, absolute stereochemistry

Pseurotin A (1) is a microbial secondary metabolite isolated from the fermentation broth of Pseudeurotium ovalis STOLK (Ascomycetes) in 1976 [1]. It has various biological activities, including induction of cell differentiation [2], inhibition of chitin synthase [3], inhibition of monoamine oxidase [4], and apomorphineantagonistic activity [5]. Pseurotin A (1) possesses a highly substituted 1-oxa-7-azaspiro[4,4]non-2-ene-4,6-dione skeleton. The structure and absolute stereochemistry of $\mathbf{1}$ have been determined by a single-crystal X-ray analysis of its 12,13-dibromo derivative [6]. The core structure of $\mathbf{1}$ is found in other natural products, too (Fig. 1). These pseurotin-related natural products also possess interesting biological activities, including apomorphine-antagonistic activity in the cases of pseurotin D [5] and F [7], antiangiogenic activity [8a], antifungal activity [8b] and synergistic activity [8b] in the case of synerazol (2) isolated

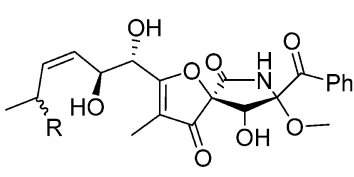

pseurotin $\mathrm{A}(\mathbf{1}): \mathrm{R}=\mathrm{H}$ pseurotin $\mathrm{B}: \mathrm{R}=\mathrm{OH}$

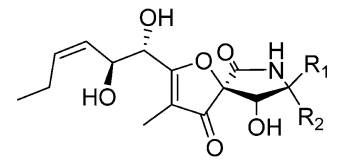

pseurotin $\mathrm{F}_{1}: \mathrm{R}_{1}=\mathrm{OH}, \mathrm{R}_{2}=\mathrm{COPh}$ pseurotin $\mathrm{F}_{2}: \mathrm{R}_{1}=\mathrm{COPh}, \mathrm{R}_{2}=\mathrm{OH}$<smiles>[R]C(C)/C=C/[C@H](O)[C@@H](O)C1=C(C)C(=O)[C@@]2(O1)O[C@@](OC)(C(=O)c1ccccc1)C(=O)N[C@@H]2O</smiles>

pseurotin $\mathrm{C}: \mathrm{R}=\mathrm{OH}$ pseurotin $\mathrm{E}(\mathbf{3}): \mathrm{R}=(=\mathrm{O})$

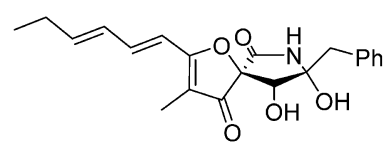

azaspirene

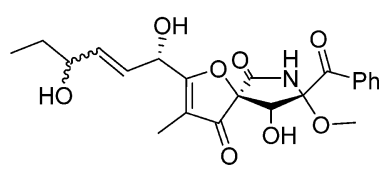

pseurotin D

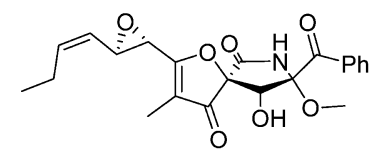

synerazol (2)

Fig. 1 Structure of pseurotin-related natural products.

M. Ishikawa ${ }^{\dagger}$ (corresponding author), T. Ninomiya: Pharmaceutical Research Center, Meiji Seika Kaisha, Ltd., 760 Morooka-cho, Kohoku-ku, Yokohama 222-8567, Japan $\dagger$ Present address: Institute of Molecular and Cellular Biosciences, The University of Tokyo, 1-1-1, Yayoi, Bunkyo-ku, Tokyo 113-0032, Japan, E-mail: m-ishikawa@iam.u-tokyo.ac.jp 
from the fermentation broth of Aspergillus fumigatus SANK 10588 in 1991 [8b], and anti-angiogenic activity in the case of azaspirene [9]. Another member of the pseurotin family, pseurotin E (3), was isolated from the fermentation broth of Pseudeurotium ovalis STOLK in 1981 [10], though its absolute stereochemistry and biological activity were not established.

Elegant total syntheses of $\mathbf{1}[11,12]$, pseurotin $\mathrm{F}_{2}[11$, 12], 2 [13] and azaspirene [14, 12] have been reported by Hayashi et al. and Tadano et al. However, these syntheses involved many steps, and are unsuitable for large-scale application to provide samples for biological testing. On the other hand, the supply of pseurotin-related natural products from fermentation is also limited, except for $\mathbf{1}$. The reported fermentation yields are $40 \mathrm{mg} /$ liter for 1 [10], $1.4 \mathrm{mg} /$ liter for 2 [8b], and $6 \mathrm{mg} /$ liter for 3 [10]. Hence, we thought chemical modification of $\mathbf{1}$ might be an attractive way to obtain large amounts of pseurotin-related natural products. In this paper, we wish to report one-pot synthesis of synerazol (2) and pseurotin E (3) from pseurotin A (1) and determination of the absolute stereochemistry of $\mathbf{3}$. Various chemical modifications of pseurotin-related natural products, including acetylation (pseurotin $\mathrm{A}$ [1] and synerazol [16]), hydrogenation (pseurotin A [15], B [10], C [10]), oxidative cleavage (pseurotin A [1], B [10], C [10]), dibromination [1] (pseurotin A), formation of acetonide [1] (pseurotin A), reduction of carbonyl group [15] (pseurotin A), and synthesis of pseurotin A from synerazol for the purpose of the determination of its absolute stereochemistry [16], have been reported.

Compound 1 was obtained from the fermentation broth of Aspergillus sp. The synthesis of $\mathbf{2}$ from $\mathbf{1}$ is illustrated in Table 1. First of all, epoxidation of the 1,2-diol of $\mathbf{1}$ under the reported Mitsunobu condition [17] did not afford 2 (entry 1). However, this reaction proceeded when $\mathrm{Cy}_{3} \mathrm{P}$ was replaced with $\mathrm{PPh}_{3}$ (entry 2). To optimize the reaction, the effects of solvents and temperature were examined. Dichloroethane (DCE) gave a better yield (entry 3). Decreasing the temperature reduced the formation of minor by-products (58\% yield, entry 4). Synthetic 2 exhibited properties identical to those of the natural product $[8 \mathrm{~b}]\left({ }^{1} \mathrm{H}-\right.$ NMR, ${ }^{13} \mathrm{C}-\mathrm{NMR}$, and optical rotation [18]). We were able to obtain 2 on a $200 \mathrm{mg}$ scale.

We decided to synthesize the $(10 R, 11 S)$-diastereoisomer of $\mathbf{2}$ to confirm the diastereoselectivity in the synthesis of $\mathbf{2}$. The $(10 R, 11 S)$-diastereoisomer $\mathbf{4}$ is generated if the hydroxyl group at the 10 position is eliminated under the above Mitsunobu conditions. NMR spectra of the $(10 R, 11 S)$-diastereoisomer $\mathbf{4}$ have not been reported, although its total synthesis was achieved [13]. Selective

Table 1 Synthesis of synerazol by Mitsunobu reaction

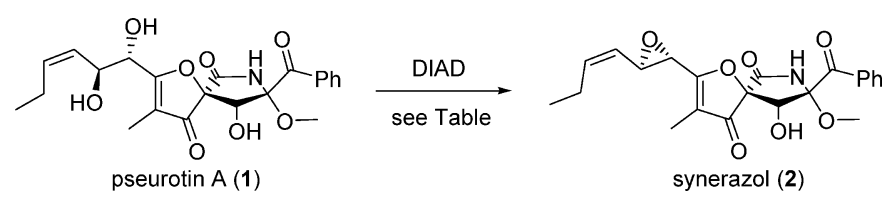

\begin{tabular}{ccccc}
\hline Entry & Phosphine & Solvents & Temp $\left({ }^{\circ} \mathrm{C}\right)$ & Time (hours) \\
\hline 1 & $\mathrm{Cy}_{3} \mathrm{P}$ & $\mathrm{THF}$ & 22 to 40 & 25 \\
2 & $\mathrm{Ph}_{3} \mathrm{P}$ & 22 to 60 & 28 \\
3 & $\mathrm{Ph}_{3} \mathrm{P}$ & $\mathrm{THF}$ & 30 & 14 \\
4 & $\mathrm{Ph}_{3} \mathrm{P}$ & $\mathrm{DCE}$ & 15 & 7.5 \\
5 & $\mathrm{Ph}_{3} \mathrm{P}$ & $\mathrm{DCE}$ & 15 & 5 \\
\hline
\end{tabular}

DIAD: diisopropyl azodicarboxylate; Cy: cyclohexyl; DCE: dichloroethane.

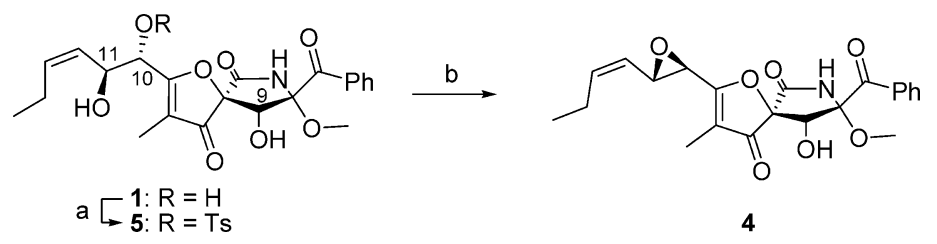

Scheme 1 Synthesis of $\mathbf{4}^{\mathrm{a}}$.

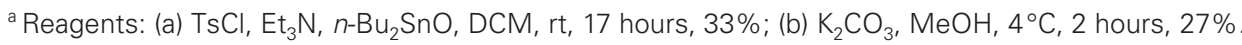




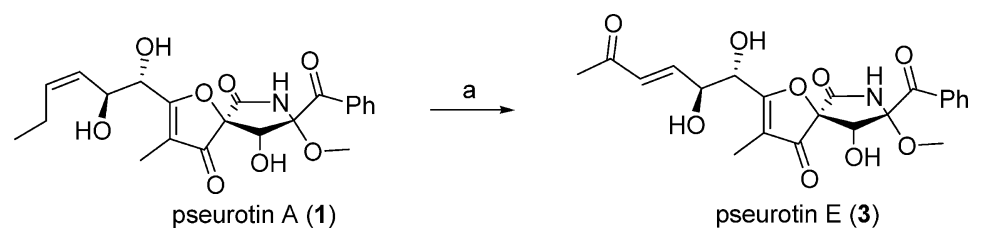

Scheme 2 Synthesis of pseurotin $E^{a}$.

${ }^{a}$ Reagents: (a) Grubbs catalyst (second generation), methyl vinyl ketone, DCM, $40{ }^{\circ} \mathrm{C}, 2.5$ hours, $57 \%$.

tosylation reaction of the 1,2-diol of $\mathbf{1}$ was achieved in the presence of dibutyltin oxide [19] to give 5 (Scheme 1). Regioselectivity of the tosyl group was assigned on the basis of ${ }^{1} \mathrm{H}-\mathrm{NMR}$ multiplicity (H-C11 (ddd, $J=5.1,7.8$, $9.5 \mathrm{~Hz}$ ), H-C10 (d, $J=7.8 \mathrm{~Hz}$ ), and H-C9 (d, $J=12.4 \mathrm{~Hz})$ ). Epoxidation under basic conditions gave 4 . The optical rotation of $4\left([\alpha]_{\mathrm{D}}^{26}-53.9^{\circ}\left(c 0.075, \mathrm{CHCl}_{3}\right)\right)$ is in good agreement with literature data $[13]\left([\alpha]_{\mathrm{D}}^{22}-49.2^{\circ}(c) 0.02\right.$, $\left.\mathrm{CHCl}_{3}\right)$ ). The $(10 R, 11 S)$-diastereomer 4 [20] proved readily distinguishable from 2 by ${ }^{1} \mathrm{H}-\mathrm{NMR},{ }^{13} \mathrm{C}-\mathrm{NMR}$, and HPLC, thereby confirming the complete diastereoselectivity of the transformation leading to 2 .

Next, we envisioned that $\mathbf{3}$ could be derived from $\mathbf{1}$ by olefin cross metathesis. Treatment of $\mathbf{1}$ with methyl vinyl ketone and second-generation Grubbs catalyst (1,3-bis(2,4,6-trimethylphenyl)-2-imidazolidinylidene)dichloro(oisopropoxyphenylmethylene)ruthenium) [21] afforded 3 in $57 \%$ yield (Scheme 2 ). The ${ }^{1} \mathrm{H}-\mathrm{NMR}$ and ${ }^{13} \mathrm{C}-\mathrm{NMR}$ spectra of synthetic 3 [22] were in good accordance with those reported for the natural product [10]. Hence, the absolute stereochemistry of pseurotin E (3) was defined. This metathesis was also applicable to the synthesis of other pseurotin E analogues (data not shown).

In summary, we have developed an efficient one-pot synthesis of synerazol and pseurotin $\mathrm{E}$ from readily available pseurotin A. This work also establishes the absolute stereochemistry of pseurotin E. We will report syntheses of pseurotin A, synerazol and various pseurotin E analogs, as well as their biological activities, in due course.

Acknowledgements The authors thank Shigeko Miki and Takako Miyara for mass spectral analysis, and Nobuaki Kushida and Go Tsujiuchi for supplying pseurotin A.

\section{References}

1. Bloch P, Tamm C, Bollinger P, Petcher TJ, Weber HP. Pseurotin, a new metabolite of Pseudeurotium ovalis Stolk having an unusual hetero-spirocyclic system. Helv Chim Acta 59: 133-137 (1976)
2. Komagata D, Fujita S, Yamashita N, Saito S, Morino, T. Novel neuritogenic activities of pseurotin A and penicillic acid. J Antibiot 49: 958-959 (1996)

3. Wenke J, Anke H, Sterner O. Pseurotin A and 8-Odemethylpseurotin A from Aspergillus fumigatus and their inhibitory activities on chitin synthase. Biosci Biotech Biochem 57: 961-964 (1993)

4. Maebayashi Y, Horie Y, Satoh Y, Yamazaki M. Isolation of pseurotin A and a new pyrazine from Pseudallesscheria boydii. Mycotoxins 22: 33-34 (1985)

5. Wink J, Grabley S, Gareis M, Zeeck A, Phillips S. Biologically active pseurotin A and D, new metabolites from Aspergillus fumigatus, process for their preparation and their use as apomorphine antagonists. Eur Pat Appl EP546475, (1993)

6. Weber HP, Petcher TJ, Bloch P, Tamm C. The crystal and molecular structure of 12,13-dibromopseurotin. Helv Chim Acta 59: 137-140 (1976)

7. Wink J, Grabley S, Gareis M, Thiericke R, Kirsch R. Pseurotin F1/F2, new metabolites from Aspergillus fumigatus, process for their preparation and their use as apomorphine antagonists. Eur Pat Appl EP546474, (1993)

8. (a) Igarashi Y, Yabuta Y, Sekine A, Fujii K, Harada K, Oikawa T, Sato M, Furumai T, Oki T. Directed biosynthesis of fluorinated pseurotin A, synerazol and gliotoxin. J Antibiot 57: 748-754 (2004)

(b) Ando O, Satake H, Nakajina M, Sato A, Nakamura T, Kinoshita T, Furuya K, Haneishi T. Synerazol, a new antifungal antibiotic. J Antibiot 44: 382-389 (1991)

9. Asami Y, Kakeya H, Onose R, Yoshida A, Matsuzaki H, Osada H. Azaspirene: a novel angiogenesis inhibitor containing a 1-oxa-7-azaspiro[4.4]non-2-ene-4,6-dione skeleton produced by the fungus Neosartorya sp. Org Lett 4: 2845-2848 (2002)

10. Breitenstein W, Chexal KK, Mohr P, Tamm C. Pseurotin B, C, D, and E. Further new metabolites of Pseudeurotium ovalis STOLK. Helv Chim Acta 64: 379-388 (1981)

11. Hayashi Y, Shoji M, Yamaguchi S, Mukaiyama T, Yamaguchi J, Kakeya H, Osada H. Asymmetric total synthesis of pseurotin A. Org Lett 5: 2287-2290 (2003)

12. (a) Aoki S, Oi T, Shimizu K, Shiraki R, Takao K, Tadano K. Total syntheses of natural pseurotins $A$ and $F_{2}$ and azaspirene. Heterocycles 62: 161-166 (2004)

(b) Aoki S, Oi T, Shimizu K, Shiraki R, Takao K, Tadano K. 
Total syntheses of natural pseurotins $\mathrm{A}, \mathrm{F}_{2}$, and azaspirene. Bull Chem Soc Jpn 77: 1703-1716 (2004)

13. Hayashi Y, Shoji M, Mukaiyama T, Gotoh H, Yamaguchi S, Nakata M, Kakeya H, Osada H. First asymmetric total synthesis of synerazol, an antifungal antibiotic, and determination of its absolute stereochemistry. J Org Chem 70: 5643-5654 (2005)

14. Hayashi Y, Shoji M, Yamaguchi J, Sato K, Yamaguchi S, Mukaiyama T, Sakai K, Asami Y, Kakeya H, Osada H. Asymmetric total synthesis of (-)-azaspirene, a novel angiogenesis inhibitor. J Am Chem Soc 124: 12078-12079 (2002)

15. Mohr P, Tamm C. Biosynthesis of pseurotin A. Tetraherdon 37: 201-212 (1981)

16. Igarashi Y, Yabuta Y, Furumai T. Determination of the absolute configuration of synerazol. J Antibiot 57: 537-540 (2004)

17. Weissman SA, Rossen K, Reider PJ. Stereoselective synthesis of styrene oxides via a Mitsunobu cyclodehydration. Org Lett 3: 2513-2515 (2001)

18. Optical rotation of synthetic 2: $[\alpha]_{\mathrm{D}}^{25}+24.0^{\circ}(c) 0.15$, $\left.\mathrm{CHCl}_{3}\right)$, natural product $[8 \mathrm{~b}]:[\alpha]_{\mathrm{D}}^{25}+22.9^{\circ}\left(c 0.55, \mathrm{CHCl}_{3}\right)$

19. Martinelli MJ, Nayyar NK, Moher ED, Dhokte UP, Pawlak JM, Vaidyanathan R. Dibutyltin Oxide Catalyzed Selective Sulfonylation of $\alpha$-Chelatable Primary Alcohols. Org Lett 1: $447-450$ (1999)
20. ${ }^{1} \mathrm{H}-\mathrm{NMR}\left(400 \mathrm{MHz}, \mathrm{CDCl}_{3}\right) \delta 1.03(3 \mathrm{H}, \mathrm{t}, J=7.6 \mathrm{~Hz}), 1.82$ $(3 \mathrm{H}, \mathrm{s}), 2.16-2.32(2 \mathrm{H}, \mathrm{m}), 3.39(3 \mathrm{H}, \mathrm{s}), 3.73(1 \mathrm{H}, \mathrm{d}$, $J=1.9 \mathrm{~Hz}), 4.02(1 \mathrm{H}, \mathrm{ddd}, J=0.7,2.0,7.8 \mathrm{~Hz}), 4.07(1 \mathrm{H}, \mathrm{d}$, $J=12.7 \mathrm{~Hz}), 4.63(1 \mathrm{H}, \mathrm{d}, J=12.5 \mathrm{~Hz}), 5.07(1 \mathrm{H}, \mathrm{ddt}, J=1.5$, 9.0, 10.7 Hz), $5.85(1 \mathrm{H}, \mathrm{brdt}, J=11.0,7.8 \mathrm{~Hz}), 7.31(1 \mathrm{H}$, brs), $7.50(2 \mathrm{H}$, brdd, $J=7.3,8.3 \mathrm{~Hz}), 7.65(1 \mathrm{H}$, brt, $J=7.3 \mathrm{~Hz}), 8.29(2 \mathrm{H}, \quad \mathrm{dd}, J=1.3,8.3 \mathrm{~Hz}) ;{ }^{13} \mathrm{C}-\mathrm{NMR}$ $\left(100 \mathrm{MHz}, \mathrm{CDCl}_{3}\right) \delta 5.1,14.0,21.3,51.7,53.1,55.1,74.0$, 89.4, 91.8, 113.8, 123.6, 128.8, 130.5, 132.4, 134.7, 141.3, $164.9,182.2,194.2,196.8 ;[\alpha]_{\mathrm{D}}^{26}-53.9^{\circ}\left(c 0.075, \mathrm{CHCl}_{3}\right)$, HPLC (Inertsil ODS-2) retention time: 14.9 minutes (synerazol), 15.7 minutes (4).

21. Chatterjee AK, Grubbs RH. Formal vinyl C-H activation and allylic oxidation by olefin metathesis. Angew Chem Int Ed 41: 3171-3174 (2002)

22. ${ }^{1} \mathrm{H}-\mathrm{NMR}\left(400 \mathrm{MHz}, \mathrm{CDCl}_{3}\right) \delta 1.70(3 \mathrm{H}, \mathrm{s}), 2.24(3 \mathrm{H}, \mathrm{s})$, $3.42(3 \mathrm{H}, \mathrm{s}), 3.62(1 \mathrm{H}, \mathrm{brd}, J=7.8 \mathrm{~Hz}), 3.92(1 \mathrm{H}, \mathrm{brd}$, $J=7.6 \mathrm{~Hz}), 4.20(1 \mathrm{H}, \mathrm{d}, J=12.2 \mathrm{~Hz}), 4.62-4.68(1 \mathrm{H}, \mathrm{m})$, $4.68(1 \mathrm{H}, \mathrm{d}, J=12.2 \mathrm{~Hz}), 4.75(1 \mathrm{H}$, br t, $J=6.1 \mathrm{~Hz}), 6.42$ $(1 \mathrm{H}, \mathrm{dd}, J=1.7,15.7 \mathrm{~Hz}), 6.88(1 \mathrm{H}, \mathrm{dd}, 4.4, J=15.8 \mathrm{~Hz})$, $7.51(2 \mathrm{H}$, br dd, $J=7.8,8.0 \mathrm{~Hz}), 7.66(1 \mathrm{H}, \mathrm{brt}, J=7.4 \mathrm{~Hz})$, $7.92(1 \mathrm{H}$, brs $), 8.31(2 \mathrm{H}$, brd, $J=8.0 \mathrm{~Hz}) ;{ }^{13} \mathrm{C}-\mathrm{NMR}$ $\left(100 \mathrm{MHz}\right.$, acetone- $\left.d_{6}\right) \delta 5.7,27.2,52.2,72.2,72.8,75.4$, $92.5,92.8,113.8,129.3,131.3,131.5,134.5,134.7,145.5$, $167.3,186.2,196.2,197.5,198.0 ;[\alpha]_{\mathrm{D}}^{22}+77.4^{\circ}(c \quad 0.31$, $\left.\mathrm{CHCl}_{3}\right)$. 